\title{
Mobile-Banking Adoption and Usage by Low-Literate, Low-Income Users in the Developing World
}

\author{
Indrani Medhi, Aishwarya Ratan, and Kentaro Toyama \\ Microsoft Research India, Scientia, 196/36, Sadashivnagar \\ Bangalore-560080, India \\ \{indranim, aratan, kentoy\} @microsoft.com
}

\begin{abstract}
Due to the increasing penetration of mobile phones even in poor communities, mobile-phone-enabled banking (m-banking) services are being increasingly targeted at the "unbanked" to bring formal financial services to the poor. Research in understanding actual usage and adoption by this target population, though, is sparse. There appear to be a number of issues which prevent low-income, low-literate populations from meaningfully adopting and using existing m-banking services. This paper examines variations across countries in adoption and usage of existing m-banking services by low-literate, low-income individuals and possible factors responsible for the same. It is observed that variations are along several parameters: household type, services adopted, pace of uptake, frequency of usage, and ease of use. Each of these observations is followed by a set of explanatory factors that mediate adoption and usage.
\end{abstract}

Keywords: Keywords: m-banking, mobile UX, financial inclusion, economic development.

\section{Introduction}

Across the developing world, there are more people with mobile phones than with bank accounts [23]. In 2007, there were over 3.3 billion phone users [6], and close to $60 \%$ of the subscribers lived in the developing world [26]. Thus, many entities with a global development focus have turned to the mobile phone as a potential platform for delivering financial services to the "unbanked". The unbanked are people without formal bank accounts who operate in a cash economy; they are limited in their ability to take out loans, maintain savings, or make remote payments, and these constraints can inhibit their economic opportunities. It is anticipated that these obstacles could be partially overcome if financial services were delivered over mobile phones.

Mobile phone-enabled banking ( $\mathrm{m}$-banking) services are already available in some countries and are increasingly being targeted at unbanked populations that are largely low-income and low-literate. However, there seem to be a number of issues which prevent this population from meaningfully adopting and using existing services $[15,22]$. Research in understanding actual usage of existing m-banking services by low-income, low-literate populations in developing countries, though, is sparse [28].

In this paper, we present a preliminary study that discusses the variations across countries in adoption and usage of existing m-banking services by low-income, low-literate 
populations and sheds some light on the possible factors that mediate adoption and usage by this target population. Through an ethnographic exploration involving interviews and qualitative observations with 90 subjects and 100 hours spent in the field in India, Kenya, the Philippines and South Africa we observe how low-income, low-literate subjects currently use (or don't use) existing m-banking services.

\section{Related Work}

\subsection{Mobile Banking User Experience in the Developing World}

There is a fair amount of literature beginning to emerge in m-banking user experiences in the developing world. One study notes that since physically wrapping digital money is difficult, gift-giving rituals may not translate to mobile money transfers [25]. A group from Nokia cautions against the metaphor of the cell phone as a digital wallet or purse, because owners have different mental associations and behaviors for mobiles [12]. One emerging issue, with important implications for our discussion on adoption and usage, is that of trust and trustworthiness. This is a complex concept, as people can trust (or distrust) various interrelated parts of the m-banking system; including themselves to execute a transaction effectively [9, 14, 18]. Another study in user interfaces for mobile money-transfers explores whether electronic access to complex financial services is enough to bring formal financial services to the unbanked, and, if so what sort of user interface is best [19].

Other works focus on broader issues of regulatory choices and business models which affect adoption and usage of these services [8, 15, 22, 23, 26,].

\subsection{Mobile Phone User Experiences for Low-Literacy Users}

There is some amount of research that looks specifically at mobile phone user interfaces for low-literacy users. Much of this work makes design recommendations voice feedback $[20,21]$, speech interfaces $[10,21,24]$, fewer menus and dedicated buttons [17], which make sense for low-literate users. Others have questioned the suitability of menu-based navigation for novice users [16].

Again there is work that looks beyond the user interface at coping mechanisms of illiterate and semi-literate users when confronted with traditional mobile phone interfaces $[11,13]$.

\subsection{Mobile Phones for Poor Communities}

The phenomenal market penetration of the mobile phone extends even into some of the world's most impoverished regions. Although it would be a mistake to overestimate its penetration in poor communities, in those areas that have mobile phone service, it's safe to say that many of the (comparatively) wealthier households own mobiles. As a result, there has been an explosion of interest in mobile phones and how they can contribute to socio-economic development, and we point readers to the twenty articles recently selected by the GSMA Development Fund [5]. Among the papers cited are those that highlight direct economic benefits to microentrepreneurs, 
methods of remote money transfer, and entire businesses based on selling talk time directly to neighbors.

The work presented in this paper occurs at the unexplored intersection of these three streams of research. The domain of m-banking being targeted towards lowliterate, low-income populations in the developing country context give rise to new questions about how effectively these users are able to adopt and use existing services. This paper contributes novel insights about the determinants that affect the adoption and usage of mobile-banking services by this population.

\section{Study Context and Methods}

We studied five m-banking services - Globe Telecom's GCash in the Philippines, Safaricom's M-PESA and Equity Bank's Eazzy 24x7 in Kenya, WIZZIT in South Africa, and Eko in India. Each of the services had a different paradigm for mobile banking both in terms of the service design as well as the UI $[1,2,3,4,7]$

We conducted a total of 90 interviews and qualitative user studies: 26 in New Delhi and Bangalore, India, 11 in Nairobi, Kenya, 30 in Bohol, Philippines, and 23 in Cape Town and Globersdale, South Africa. (Variations in number are due in part to the complexity of identifying customers with the characteristics we were seeking.) Our hope was that by investigating most of the developing geographies with active mobile payment schemes, we could get a better overall sense for the recurring issues.

We looked for varying degrees of experience with using existing m-banking services: (a) those that did not use or own a mobile phone; (b) those that owned or used mobile phones but did not use any kind of m-banking systems; and (c) those that used m-banking systems. 40 of our subjects were in the first category, 34 in the second and 16 in the third. These traits make them an ideal user population with which to explore issues mediating adoption and usage of these services.

Our subjects had three common background traits: (1) functional illiteracy or semiliteracy but partial numeracy; (2) low levels of formal education (highest education attained being schooling up to the eighth grade of the K-12 education system or its equivalent across the four countries); (3) zero experience with personal computers.

To identify subjects with these characteristics, we worked with intermediary organizations. In order to reduce sampling biases based on the nature of the organization, we worked with for-profit corporations running the m-banking services, as well as with non-profit organizations working with poor populations. This is still far from having randomized samples at an individual level, and the appropriate cautions about generalizing from our results apply.

Our subjects were typically domestic workers and daily wage laborers like plumbers, carpenters, construction workers, mechanics, vegetable vendors, weavers, farm hands, fishermen, drivers, etc. Household income ranged from USD 20 - USD 200 per month. Some of our subjects had television sets, music players and gas burners, but these were not owned by all households. A few had seen computers in person (but again, none had ever used them). Naturally, differences also exist across geographies. The subjects' primary languages were Kannada, Hindi and Tamil in India, Tagalog in Philippines, Afrikaans, Xhosa and Zulu in South Africa and Kiswahili in Kenya. 
The interviews were one-on-one, open-ended conversations that lasted for at least an hour. Questions and discussion themes included basic demographic information, access and use of financial services, and access and use of mobile phones. The study involved over 100 hours spent in the field. We visited individuals at their homes in order to talk to our subjects in a comfortable environment, and to observe their living environments. We also conducted interviews at m-banking agent locations where transactions took place. We conducted qualitative user studies with our subjects for the locally available m-banking service in which they were given a set of usability tasks to perform both on their own handsets and on mobile phones provided by us (in order to determine how much of their usage was by rote memorization).

All users were compensated for their time, at the end of the study. We consulted the intermediary organizations to establish the right mode and amount. Participants without mobile phones were given gift cards for local stores and those with mobile phones were given talk-time cards roughly equivalent to half a day's wage.

\section{Observations}

Across the locations and providers studied, we observed substantial variation in the adoption and usage of m-banking services by low-income low-literate individuals. The variations were along a number of parameters: household type, key service adopted, pace of uptake, frequency of usage, and ease of use. Some of the key variations noted are described in this section, with each observation followed by a set of likely explanatory factors.

\subsection{Household Characteristics}

It did not seem to be the case that only rural or only urban households in any given country had adopted the m-banking service. Instead, we found that among our respondents, certain types of rural and urban households had adopted the m-banking service. Some sections of the poor seemed to be active users, others infrequent users, while others did not adopt the service at all.

Why?

Location of family members. In Kenya, certain subjects' families had a young male member working in the city, while the rest of the family continued to farm in the village. This specific form of rural-urban migration that involved a geographically 'split' family corresponded with a pre-existing need to frequently send money from urban to rural locations. As a result, such families saw high adoption of M-PESA [see 28, 29]. Similarly, urban residents with immediate or distant family members in rural areas used M-PESA to send money transfers to their relatives. In the other direction, rural households with a child in an urban school or college periodically used the service to transfer fees to a person at their child's educational institution and/or send their children pocket money. Conversely, entirely rural households had not adopted the M-PESA service in Kenya. Their relatives and family were all co-located, and so all transactions were local. As a result, they had no need for a long-distance money transfer service, the key offering of M-PESA. [29] 
Employment. The uptake of m-banking services in a location seemed to also depend on whether adoption was forced or optional depending on the kind of employment of the household's wage earners. All the 7 users of WIZZIT in South Africa we spoke with were farmhands at farms (with 50-70 employees) that were signed on by WIZZIT for salary accounts for the farms' employees. The monthly wages were remitted to the WIZZIT salary accounts of each of these employees by the farms. None of the farmhands we spoke with had adopted the service on their own.

\subsection{Services Adopted}

While a broad range of financial transaction services were offered through the $\mathrm{m}$ banking platform in certain cases (GCash and M-PESA), the service that saw aggressive adoption by our respondents varied. In Kenya, for instance, though information services (bank balance check, transaction history, etc.) were offered through Equity Bank's SMS banking service, and money transfers and airtime top-up services were offered by M-PESA, it was only the domestic money transfer service that had seen widespread uptake. GCash in the Philippines was used primarily for international remittance transfers, and much less for domestic money transfers.

Why?

Match between offerings and need. In the case of South Africa, we did not observe as strong a need for domestic remittances. Instead we saw that 5 out of 7 Wizzit users, were migrant workers from Zimbabwe, who expressed a strong need for international remittances. However at the time this study was conducted, WIZZIT in South Africa was only offering domestic remittances. In Kenya, while airtime purchase was offered via M-PESA, none of our respondents, even those who actively used M-PESA for money transfers had begun buying airtime through the m-payment channel [29]. When asked why, they said the 'bamba' prepaid talktime cards were so easy to get and use. For them, that was "enough".

Pricing vis-à-vis alternate channels. The pricing of the m-banking service with respect to other formal and informal remittance channels available in a location, was a determinant of how our subjects adopted and used the m-banking service. In Kenya, one of the reasons for some users to shift to M-PESA for remittance transfers was because it was half the price of the formal alternative, i.e. the postal money order that they were currently using. For transacting with or between the unbanked, compared to the nearest formal, secure alternatives, M-PESA was lower cost, though it remains more expensive than using informal channels like family or friends [29]. On the other hand in the Philippines, 9 out of 30 subjects mentioned that they would prefer to use the local bus line because it costs less. They could simply hand over cash in an envelope to the driver traveling in the direction of the recipient's location. In the case of 7 out of the 9 subjects, this transfer had no explicit cost given that the driver was a friend or a family member of the sender or the recipient.

Reliability with respect to informal channels. Our subjects in South Africa and Kenya would use WIZZIT and M-PESA respectively because of the reliability these m-banking services provided compared to informal channels. 8 out of 34 subjects 
described sending money through friends and relatives had no explicit cost, but sometimes the money never reached the intended recipient. Instead, with m-banking, doing the transfer directly to the recipient's phone and receiving confirmation for the same did not leave any uncertainty on whether the money had reached the intended recipient or not.

Service paradigm. The m-banking service paradigm seemed to affect the way our subjects were using these channels for financial transactions. As mentioned earlier, for GCash, Eko and M-PESA, the service allowed for cash transactions to be done at cash-in/cash-out corner shops, and for WIZZIT and Equity, bank branches were used for cash deposits and ATMs used for cash withdrawals. We observed that 7 out of 9 clients of Equity had debit cards and used them primarily to withdraw money at ATMs. However, none of the subjects had ever made a deposit at an ATM, with some not knowing how it worked or if it was even possible. Instead they would visit the bank branch for making a deposit [29]. In the case of M-PESA and Eko, however, the corner shop paradigm seemed to encourage both deposits and withdrawals as frequently as 5 times per week.

\subsection{Pace of Uptake}

The pace at which various m-banking services have spread in the low-income segment has differed substantially from country to country, and even between service providers. The overall pace of adoption has varied from 2 million M-PESA customers signed up in the first year in Kenya, to just over 50,000 WIZZIT customers signed up in South Africa over 2 years. There has been rapid uptake of the M-PESA service by low-income, low-literate customers in Kenya, vs. virtually no uptake by the target segment in the Philippines. In both India and South Africa, the uptake of the offered m-banking services by low-income households has been slow.

Why?

Level of awareness. The level of awareness about availability and features of mbanking services affects the way in which our respondents were adopting (or not adopting) these services. 21 out of 30 subjects in the Philippines, 11 out of 23 in South Africa and 22 out of 26 in India had never heard of m-banking channels. Among the subjects who were aware, the perception was that the service would be expensive because it involves the use of technology.

Trust. Among our subjects, there were issues of trust which seemed to mediate the adoption of m-banking channels for remittances. 7 out of 30 subjects in the Philippines and 6 out of 23 subjects in South Africa were concerned about the money transfer not reaching the recipient's phone and were wary about whether it would be possible to retrace lost money in case the recipient did not receive a remittance that was initiated. In contrast, adopters of M-PESA in Kenya had acquired a great deal of trust in the new channel, primarily due to the clear marketing by the provider Safaricom and the strong pre-existing ties with the local prepaid talktime agents, who 'sold' the new service as a trustworthy channel to their low-income customers. 


\subsection{Frequency of Usage}

In places like Kenya, M-PESA is used by those who have an active need as frequently as 2-3 times a month, whereas in the Philippines, the m-banking channel is hardly used with any frequency. In South Africa, despite having accounts, low-income customers did not conduct banking transactions on their mobile phone.

Why?

Agent proximity and ubiquity. The proximity and ubiquity of m-banking agent locations (cash-in/cash-out stores for GCash, Eko, and M-PESA, and bank branches and ATMs for WIZZIT and Equity) seemed to be an important determinant affecting the motivation for adoption and frequency of usage by our subjects. In Kenya for most of our respondents, getting to the nearest M-PESA agent was in many cases faster than getting to the nearest Post Office or bank branch, given the number of Safaricom agents in different locations who offered this service especially in lowincome residential areas. The proximity to the nearest agent location/ATM also seemed to affect users' frequency of withdrawal. [29]. Similarly in India, for 3 out of 4 users, the proximity of the Eko agents which resulted in bringing down travel cost to minimal was a key attraction. Whereas in the Philippines, for 19 out of 30 subjects the absence of GCash agent locations especially in rural areas seemed the deterrent in adoption of m-banking services.

Transaction time at agent stores. The time saved by transacting at an m-banking agent store location (cash-in/cash-out stores for Eko, GCash and M-PESA), where there was likely to be lower customer traffic, was important in raising the convenience of these services. Subjects across these three locations, whether banked or not, associated banks with long queues. It was important that the agents were open later in the evenings (unlike banks operating only during banking hours from $9 \mathrm{am}-5 \mathrm{pm}$ ). Another feature that impressed users was the speed with which the transaction was completed. Even in cases where there were delays in receiving the confirmation SMS, it was a matter of minutes or hours.

\subsection{Ability to Transact on the Application}

There was significant variation in users' ability to conduct the m-banking transaction on their mobile phones themselves. Despite having their own M-PESA accounts, for instance, 3 of 8 M-PESA users transacted on their account only through peers or their local agents. They did not access the application on their own device, instead handing over their money and sometimes their phone to a peer or agent, and having them perform the transaction.

Why?

Interaction Design. There were a number of challenges encountered by our subjects in interacting with the m-banking services and navigating through mobile phones in general which mediated their ability to use these services effectively. Of the total 90 subjects, 56 ( 40 non-users of mobile phones +16 existing mobile phone users) were initially unable to understand or navigate hierarchical menus as they currently exist. Usability tasks showed that few had an abstract hierarchical model in mind. Furthermore, functions buried in deep hierarchies were less discoverable to them, especially 
when functions were categorized under seemingly un-related functions. Again out of the total 90 subjects, 48 (40 non-users of mobile phones +8 voice-only users) did not initially understand vertical scrollbars. These subjects did not realize that there were functions "beneath" what was displayed. As many as 45 users had difficulty with soft keys - associating the numerical index with the function in an enumerated list of functions and/or building mental models when buttons located alongside the display resulted in different functions dependent on the application. Again out of the total 27 voice-only users, 24 subjects were unable to type even a single word, much less an entire text message. For constructing a USSD syntax comprising of digits and symbols ("*" and "\#"), our subjects were comfortable typing the digits, but could not locate the symbols. Again subjects, most of whom were not fluent in English, had difficulty reading the text portions of the receipts which were entirely in English (except in the case of M-PESA where they were in English and Kiswahili). But almost all could identify the numbers and what they meant. However, subjects still had difficulty with receipts indicating multiple transactions. Finally, since most of our subjects were unbanked, they were not familiar with the vocabulary of banking. "View last transaction," "Get balance", "Change PIN", and so forth, were all alien concepts, in the absence of detailed explanation.

Degree of human mediation. The degree of mediation by m-banking agents is an important determinant affecting how these services are adopted and used especially by low-literate users. In the current state, registration and trouble-shooting for the mbanking services are done by human intermediaries (agent locations for GCash, Eko, M-PESA, Wizzkids for WIZZIT and ATM lobby assistants for Equity). All of the services provide instruction manuals and information brochures for assisting users. Most of these manuals are overloaded with textual information, mostly in English. For low-literate users, these are all but useless, since the accompanying visuals often are not self-explanatory. Some of the services offer local-language manuals, but these too are complex and laden with banking jargon. For the most part, our subjects did not even attempt to read these manuals, and human mediation was critical for successful transactions.

\section{Conclusion}

In this paper, we explored a number of factors that mediate the ability of low-income, low-literate users in developing country contexts to adopt and use existing m-banking systems. We studied five existing m-banking services across India, Kenya, the Philippines and South Africa and conducted interviews and qualitative user-studies with 90 subjects in these four countries. Our observations were around variations in adoption and usage across locations and potential factors responsible for the same. The variations were along a number of parameters: household type, key service adopted, pace of uptake, frequency of usage, and ease of use. We followed each observation by a set of likely explanatory factors that mediate adoption and usage.

While preliminary, this study points to the set of variables that together influence the adoption and intensity of usage of m-banking services by low-income, low-literate users. Understanding these variations in m-banking usage is imperative to evolving accurate understandings of impact. In future work, we expect to explore improvements 
in UI/UX for specific m-banking services targeted at low-literate clients, understand the optimal role of mediators in driving usage, as well as arrive at rigorous estimates of welfare impact by varying usage profiles.

\section{References}

1. EKO, http://www.eko.co.in/pilot.html

2. Equity Bank, http://www. equitybank.co.ke/

3. M-PESA, http://www. safaricom.co.ke/index.php?id=228

4. GCASH, http://www. GCash. com.ph/

5. GSMA Development Fund, http: / /www.gsmworld.com/developmentfund/ report_top20_form.shtml

6. ITU ICT Eye, http: //www.itu.int/ ITU- D/icteye/Reporting/ShowReportFrame.aspx?ReportName=/ WTI/CellularSubscribersPublic\&RP_intYear $=2007 \& R P \_$intLanguageID $=1$

7. WIZZIT, http://www.WIZZIT.co.za/

8. infoDEV: Micro-payment systems and their application to mobile networks. Micro (2006), http://infodev.org/files/ 3014_file_infoDev.Report_m_Commerce_January.2006.pdf

9. Benamati, J.S., Serva, M.A.: Trust and distrust in online banking: Their role in developing countries. Information Technology for Development 13(2), 161-175 (2007)

10. Boyera, S.: The Mobile Web to Bridge the Digital Divide? In: The IST-Africa Conference 2007, Maputo, Mozambique (2007)

11. Chipchase, J.: Literacy, Communication, and Design. In: UIAH (2006)

12. Chipchase, J., Persson, P., Piippo, P., Aarras, M., Yamamoto, T.: Mobile essentials: field study and concepting. In: Proc. Designing for User eXperience Conference, San Francisco, USA (2005)

13. Chipchase, J.: Understanding Non-Literacy as a Barrier to Mobile Phone Communication (2005),

http: //research.nokia.com/bluesky/ non-literacy-001-2005/index.html (retrieved September 16, 2008)

14. Donner, J.: M-Banking and M-Payments Services in the Developing World: New channel, same ties? In: The panel on living and livelihoods at HOIT 2007: Home/community oriented ICT for the next billion, IIT Madras, Chennai, India, August 23 (2007)

15. Ivatury, G., Pickens, M.: Mobile phone banking and low-income customers: evidence from South Africa. Consultative group to assist the poor (CGAP) and the United Nations Foundation, Washington (2006)

16. Jones, M., Buchanan, G., Thimbleby, H., Marsden, G.: User interfaces for mobile web devices www9 mobile workshop position paper. In: Proc. 9th International World Wide Web Conference (2000)

17. Lehrman, S.: Dialing in. Mobile phones target the world's nonreading poor. Scientific American 296(5), 30-31 (2007)

18. Morawczynski, O., Miscione, G.: Examining Trust in Mobile Banking Transactions in Kenya: The Case of Value-Ex. In: Draft Submission for HCC8 Conference (2007) 
19. Medhi, I., Nagasena, G.S.N., Toyama, K.: A Comparison of Mobile Money-Transfer UIs for Non-Literate and Semi-Literate Users. In: Proc. ACM Conference on Computer Human Interaction, Boston, USA (2009)

20. Parikh, T., Javid, P., Sasikumar, K., Ghosh, K., Toyama, K.: Mobile Phones and Paper Documents: Evaluating a New Approach for Capturing Microfinance Data in Rural India. In: ACM Conference on Computer-Human Interaction (CHI), Montreal, Canada (2006)

21. Plauche, M., Prabaker, M.: Text-Free User Interfaces. In: ACM Conference on Computer Human Interaction, Montreal, Canada (2006) (working papers)

22. Porteous, D.: Just how transformational is m-banking? (2007), http: / /www. finmarktrust.org.za/accessfrontier/Documents / transformational_mbanking.pdf (retrieved November 1, 2007)

23. Porteous, D.: The enabling environment for mobile banking in Africa. DFID, London (2006)

24. Sherwani, J., Ali, N., Mirza, S., Fatma, A., Memon, Y., Karim, M., Tongia, R., Rosenfeld, R.: HealthLine: Speech-based Access to Health Information by Low-literate Users. In: Proc. IEEE/ACM Int'l Conference on Information and Communication Technologies and Development, Bangalore, India (2007)

25. Singh, S.: The Digital Packaging of Electronic Money. In: Aykin, N. (ed.) Usability and Internationalization. Global and Local User Interfaces, pp. 469-475. Springer, New York (2007)

26. UNCTAD, Information Economy Report 2007-2008: Science and Technology for Development - The New Paradigm of ICT, Geneva: United Nations Conference on Trade and Development (2008)

27. Vaughan, P.: Early lessons from the deployment of M-PESA, Vodafone's own mobile transactions service. In: Coyle, D. (ed.) The Transformational Potential of M-Transactions, vol. 6, pp. 6-9. Vodafone Group, London (2007)

28. Morawczynski, O.: Surviving in the "dual system": How M-PESA is fostering urban-torural remittances in a Kenyan Slum. Working paper, Social Studies Unit, University of Edinburgh (January 2008)

29. Ratan, A.L.: Using technology to deliver financial services to low-income households: a preliminary study of Equity Bank and M-PESA customers in Kenya, Microsoft Research Technical Report (June 2008) 